\title{
Virologic and Lipoprotein Changes after Halving Ritonavir Boosting in HIV-Infected Patients Stabilized on Once-Daily Fosamprenavir plus Abacavir/Lamivudine
}

\author{
Dushyantha T. Jayaweera', Gary E. Pakes ${ }^{2}$ \\ ${ }^{1}$ University of Miami Miller School of Medicine, Miami, USA; ${ }^{2}$ GlaxoSmithKline, Research Triangle Park, USA. \\ Email: DJayawee@med.miami.edu
}

Received November $3^{\text {rd }}, 2011$; revised December $15^{\text {th }}, 2011$; accepted March $14^{\text {th }}, 2012$

\begin{abstract}
Background: The effect of reducing ritonavir boosting doses on the efficacy and safety of fosamprenavir-based regimens has not been well studied. Methods: In a 52-week, phase 4, open-label, single-center pilot study, 26 antiretroviral-naïve, HIV-infected patients with viral loads $>1000$ copies $/ \mathrm{mL}$ received induction with fosamprenavir/ritonavir 1400 $\mathrm{mg} / 200 \mathrm{mg}$ plus abacavir/lamivudine $600 \mathrm{mg} / 300 \mathrm{mg}$ once daily for 28 weeks. Patients achieving a viral load $<50$ copies $/ \mathrm{mL}$ at week 28 were given maintenance therapy for 24 subsequent weeks with half the ritonavir dose $(100 \mathrm{mg})$ plus the usual fosamprenavir, lamivudine, and abacavir doses. Results: The study population $(\mathrm{n}=26)$ was diverse with respect to sex (14 females/12 males) and race (16 black, 10 white). Baseline median viral load was $4.93 \log _{10} \operatorname{copies} / \mathrm{mL}$ and CD4+ count $110 / \mathrm{mm}^{3}$. Of 12 induction/maintenance completers, $10(83 \%)$ achieved viral loads $<50$ copies $/ \mathrm{mL}$ by maintenance-week 24. Median CD4+ count increased from $110 / \mathrm{mm}^{3}$ at baseline to $292 / \mathrm{mm}^{3}$ at induction-week 28 and to $296 / \mathrm{mm}^{3}$ at maintenance-week 24 . The incidence of adverse events at maintenance-week 24 did not differ from that at induction-week $28(\mathrm{P}>0.05)$. Median fasting total-cholesterol, LDL-cholesterol, and triglycerides remained below NCEP cut-off levels. Baseline/induction-week 28/maintenance-week 24 median total-cholesterol was 130/177/183 $\mathrm{mg} / \mathrm{dL}$, LDL-cholesterol 78/107/114 mg/dL, HDL-cholesterol 33/41/43 mg/dL, total-cholesterol: HDL-cholesterol ratio 3.9/4.3/4.3, and triglycerides 93/145/119 mg/dL. During induction, total VLDL/chylomicron, LDL, and HDL particles increased; during maintenance, VLDL/chylomicron particles decreased, but LDL and HDL particle concentrations did not notably change. Conclusions: Reducing ritonavir boosting from $200 \mathrm{mg}$ to $100 \mathrm{mg}$ once daily in HIV-infected patients stabilized on once-daily fosamprenavir/abacavir/lamivudine resulted in maintenance of virologic suppression, enhanced CD4+ count, and improved triglycerides.
\end{abstract}

Keywords: Fosamprenavir; HIV Infection; Lipoproteins; Ritonavir

\section{Introduction}

Fosamprenavir, the phosphate ester prodrug of the antiretroviral protease inhibitor amprenavir, is frequently used as a component of combination antiretroviral therapy in HIV-infected patients. Fosamprenavir-containing regimens offer the flexibility of dosing either once-daily or twice-daily without regard to food or fluid requirements [1]. Once-daily fosamprenavir regimens can be prescribed only for antiretroviral-naïve patients and must be co-administered with low-dose ritonavir. The latter serves to inhibit the CYP3A4 hepatic metabolism of amprenavir, thereby increasing amprenavir plasma concentrations/exposure, elimination half-life, and antiretroviral activity [2].

The initial once-daily ritonavir boosting dose to be approved in the United States for co-use with fosam- prenavir was $200 \mathrm{mg}$. This approval was based on the findings of the SOLO study, a clinical trial that evaluated fosamprenavir/ritonavir $1400 \mathrm{mg} / 200 \mathrm{mg}$ once daily plus abacavir/lamivudine $300 \mathrm{mg} / 150 \mathrm{mg}$ twice daily and showed that $69 \%$ of 322 antiretroviral-naïve patients treated were able to achieve a viral load $<400$ copies $/ \mathrm{mL}$ at 48 weeks [3]. As ritonavir is associated with doserelated adverse gastrointestinal events and unfavorable lipid changes [4-6], using the lowest ritonavir boosting dose to push amprenavir concentrations to well within the clinically effective range would be expected to optimize the tolerability of fosamprenavir/ritonavir regimens. In view of this, a ritonavir boosting dose lower than 200 $\mathrm{mg}$ once daily $-100 \mathrm{mg}$ once daily — was investigated in studies of patients receiving once-daily fosamprenavircontaining regimens [7-16].

COL10053 showed that once-daily ritonavir $100 \mathrm{mg}$ 
boosting of fosamprenavir $1400 \mathrm{mg}$ provided a mean plasma amprenavir trough concentration $\left(\mathrm{C}_{\tau}\right)$ of $0.86 \mu \mathrm{g} / \mathrm{mL}$ [17], which is 6-fold higher than the mean amprenavir protein binding-adjusted $50 \%$ inhibitory concentration $\left(\mathrm{IC}_{50}\right)$ for wild-type virus $(0.146 \mu \mathrm{g} / \mathrm{mL})$ [18] and 2.5fold above the historical $\mathrm{C}_{\tau}$ value observed with unboosted fosamprenavir $1400 \mathrm{mg}$ twice daily $(0.35 \mu \mathrm{g} / \mathrm{mL})$ [19]. The results of this pharmacokinetic study led to Food and Drug Administration approval of ritonavir 100 $\mathrm{mg}$ once daily for boosting fosamprenavir $1400 \mathrm{mg}$ oncedaily-based regimens in treatment-naïve HIV populations in the United States [20].

There are limited data available describing whether changes in efficacy or safety occur when HIV-infected patients stabilized on a fosamprenavir/ritonavir $1400 \mathrm{mg} /$ $200 \mathrm{mg}$ once-daily regimen have their ritonavir boosting dose reduced to $100 \mathrm{mg}$ once daily. The purpose of COL101295 was to explore the clinical sequelae of such a switch over 24 weeks when it follows 28 -week treatment induction with fosamprenavir/ritonavir $1400 \mathrm{mg} / 200$ $\mathrm{mg}$ once daily plus abacavir/lamivudine $600 \mathrm{mg} / 300 \mathrm{mg}$ once daily in antiretroviral-naïve, HIV-infected patients. In addition, an analysis of the effect of treatment on lipid particles was conducted.

\section{Methods}

In this 52-week, phase 4, open-label, single-center pilot study, 26 antiretroviral-naïve, HIV-infected patients with viral load $>1000$ copies $/ \mathrm{mL}$ and any $\mathrm{CD} 4+$ cell count received induction treatment with fosamprenavir/ritonavir $1400 \mathrm{mg} / 200 \mathrm{mg}$ plus abacavir/lamivudine 600/300 $\mathrm{mg}$ once daily for 28 weeks. Patients who achieved a viral load $<50$ copies $/ \mathrm{mL}$ at week 28 were given maintenance therapy for 24 subsequent weeks with half the ritonavir dose $(100 \mathrm{mg})$ plus the usual fosamprenavir, lamivudine and abacavir doses. Fosamprenavir was administered as two 700-mg tablets of Lexiva ${ }^{\circledR}$ (GlaxoSmithKline, Research Triangle Park, North Carolina), abacavir $600 \mathrm{mg}$ as two $300-\mathrm{mg}$ tablets of Ziagen ${ }^{\circledR}$ (GlaxoSmithKline, Research Triangle Park, North Carolina), lamivudine as two 150-mg tablets of Epivir $^{\circledR}$ (GlaxoSmithKline, Research Triangle Park, North Carolina), and ritonavir as one or two 100-mg soft-gel capsules of Norvir $^{\circledR}$ (Abbott Laboratories, North Chicago, Illinois).

The primary study endpoints were the proportion of patients achieving a viral load $<50$ copies $/ \mathrm{mL}$ at the end of the induction and maintenance periods, and change from baseline in $\mathrm{CD} 4+$ count and safety/fasting lipid profile at these time points. Viral load (HIV-1 RNA) and CD4+ were measured at baseline (week 0), weeks 4, 12, 16, 20, 24 and 28 (induction period), and at weeks 32, 40, 48, and 52 (maintenance period) using the Roche Amp- licor MONITOR Ultrasensitive assay (version 1.5; LLOQ 50 copies $/ \mathrm{mL}$ ) (Roche Diagnostics, Branchburg, New Jersey) and HIV-1 MONITOR Version 1.0 polymerase chain reaction assay (LLOQ, 400 copies $/ \mathrm{mL}$ ) (Roche, Nutley, New Jersey). Virologic failure was said to occur, and require the patient discontinuing their study treatment regimen, if viral load remained $>200$ copies/ $\mathrm{mL}$ at induction-week 24 or if there were two consecutive viral load levels of $\geq 1000$ copies $/ \mathrm{mL}$ observed within a 1- to 2-week period after at least two consecutive (separated by 1-2 weeks) viral load values of $<200$ copies $/ \mathrm{mL}$ ). CD4+ T lymphocyte cell count was assessed by flow cytometry.

Patients were monitored for adverse events, laboratory abnormalities, and any HIV-related illnesses at baseline (week 0) and weeks 4, 12, 16, 20, 24, 28, 32, 40, 48, and 52. NMR (LipoMed Inc., Cambridge, Massachusetts) was used to measure the quantity and size of LDL, HDL, IDL, and VLDL/chylomicron particles at baseline, week 28 (end of induction), and week 52 (end of maintenance). Adherence was assessed by pill count (pills counted in returned vials of study medication) by the study site personnel at each patient visit and by patient self-report. Statistics were primarily descriptive in the observed population, and included change from baseline in viral load, CD4+ count, lipids, and lipoproteins, and tabulation of adverse events and abnormal laboratory values. A Fisher exact test was performed to compare the total adverse event incidence at week 28 of the induction regimen with that at week 24 of the maintenance regimen (week 52 of study). A P value of $<0.05$ for this comparison was considered statistically significant.

\section{Results}

\subsection{Patient Characteristics}

The baseline characteristics of the patient population are shown in Table 1. Fifteen patients completed the 28week induction phase, and 12 completed both the induction and maintenance study phases. Fourteen patients

Table 1. Characteristics of the study population.

\begin{tabular}{lc}
\multicolumn{1}{c}{ Number of patients } & 26 \\
\hline Mean age, years (range) & $40(21-57)$ \\
Sex & $12(46 \%)$ \\
Male & $14(54 \%)$ \\
Female & $16(62 \%)$ \\
Race/Ethnicity & $10(38 \%)$ \\
African American & $4.93(3.88-6.07)$ \\
Caucasian & \\
Median HIV-1 RNA, $\log _{10}$ copies $/ \mathrm{mL}$ (range) & $110(11-308)$ \\
\hline
\end{tabular}

${ }^{\mathrm{a}}$ Includes 5 hispanics. 
prematurely discontinued due to loss to follow-up (6), protocol violation (4), moving away (2), or suspected abacavir-related hypersensitivity reaction (2).

\subsection{Efficacy}

In the 15 patients who completed the induction phase, 11 $(73 \%)$ had a viral load $<50$ copies $/ \mathrm{mL}$ and $12(80 \%)$ a viral load of $<400$ copies $/ \mathrm{mL}$ at induction-week 28 . In the 12 completers of both treatment phases, $10(83 \%)$ patients had a viral load level $<50$ copies $/ \mathrm{mL}$ (Figure 1(a)) and $11(92 \%)$ a viral load of $<400$ copies/mL by maintenance-week 24 (Figure 1(b)). CD4+ count increased from a baseline median of $110 / \mathrm{mm}^{3}$, to $292 / \mathrm{mm}^{3}$ at induction-week 28 , and finally to $296 / \mathrm{mm}^{3}$ at maintenance-week 24 (Figure 1(c)).

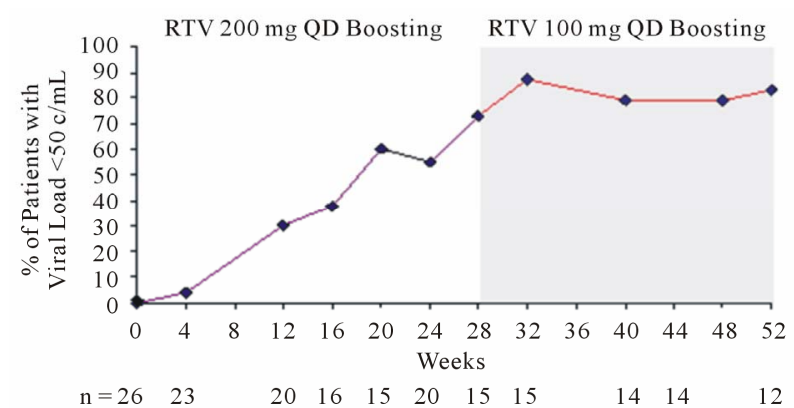

(a)

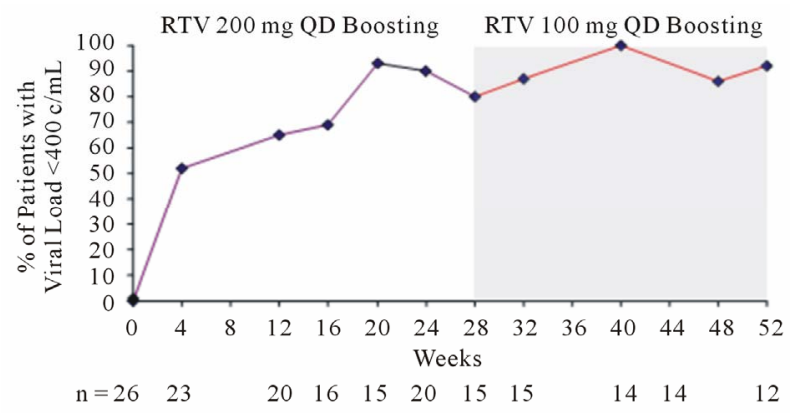

(b)

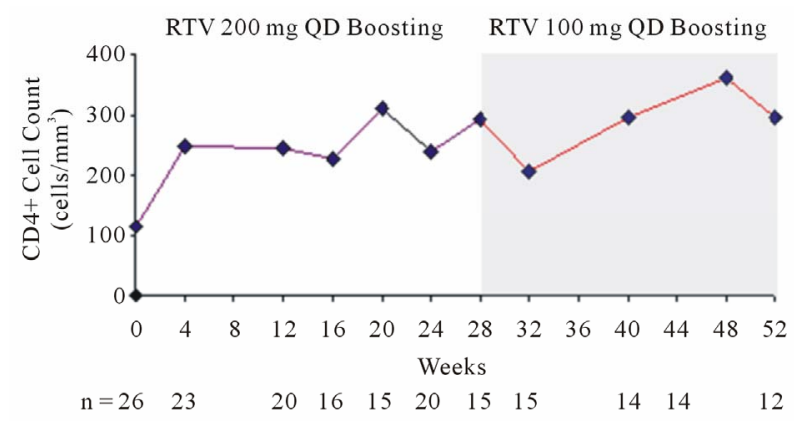

(c)

Figure 1. Change in viral load with respect to proportion of patients achieving HIV-1 RNA $<50$ copies/mL (a) and $<\mathbf{4 0 0}$ copies/mL (b); Change in CD4+ cell count is shown in (c).

\subsection{Safety}

Adverse events generally were reported during the first 4 weeks of the study, with few reports subsequently. Potentially drug-related adverse events included abdominal discomfort (1), anemia (1), depression (1), odynophagia (1), rash (3), hypercholesterolemia (1), and hypertriglyceridemia (2) during induction, and hypercholesterolemia and hypertriglyceridemia (2) during maintenance. The incidence of adverse events at maintenance-week $24 \mathrm{did}$ not differ from that at induction-week $28(\mathrm{P}>0.05)$. Lipid analysis showed that median fasting total-cholesterol, LDL-cholesterol, and triglycerides remained below National Cholesterol Education Program (NCEP) cut-off levels [21] (Figure 2). No hypolipidemic medications were prescribed during the study. The greatest increase in median total-cholesterol levels occurred between baseline and induction-week 28 (from 130 to $177 \mathrm{mg} / \mathrm{dL}$ ), as was the case with LDL-cholesterol (from 78 to 107 $\mathrm{mg} / \mathrm{dL}$ ), HDL-cholesterol (from 33 to $41 \mathrm{mg} / \mathrm{dL}$ ), triglycerides (from 93 to $145 \mathrm{mg} / \mathrm{dL}$ ), and the total-cholesterol: HDL-cholesterol ratio (from 3.9 to 4.3) (Figure 3). After reducing the ritonavir boosting dose to $100 \mathrm{mg}$ once daily, little or no change was seen over the ensuing 24-week maintenance period in median total-cholesterol ( $+6 \mathrm{mg} / \mathrm{dL}$ [to $183 \mathrm{mg} / \mathrm{dL}$ at week 24]), LDL-cholesterol $(+7 \mathrm{mg} / \mathrm{dL}$ [to $114 \mathrm{mg} / \mathrm{dL}$ ]), HDL-cholesterol $(+2 \mathrm{mg} / \mathrm{dL}$ [to $43 \mathrm{mg} / \mathrm{dL}$ ]), and total-cholesterol: HDL-cholesterol ratio (no change, remaining 4.3), although triglycerides fell notably ( $-26 \mathrm{mg} / \mathrm{dL}$ [to $119 \mathrm{mg} / \mathrm{dL}])$.

\subsection{Lipoprotein Particle Analysis}

Table 2 compares lipid particle concentrations at baseline, end of induction, and end of maintenance. Between baseline and the end of the induction phase, total VLDL/ chylomicron particles doubled in quantity and subclasses of these particles increased by $62 \%$ to $166 \%$. Following

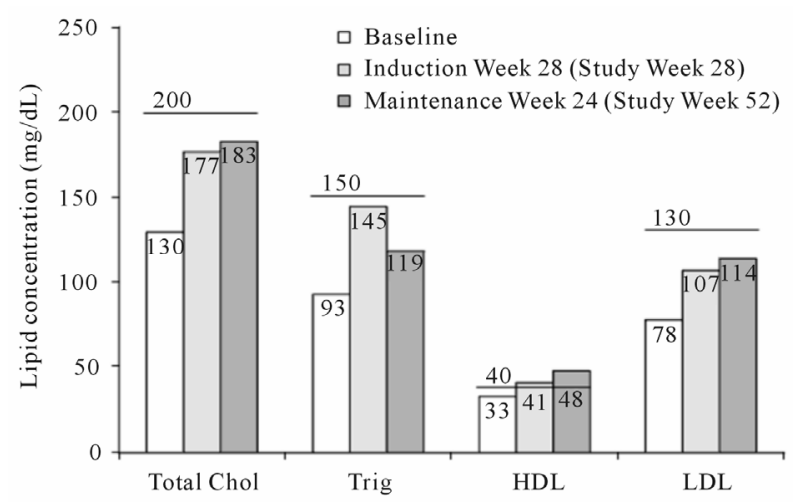

Figure 2. Lipid concentrations at baseline, induction-week 28, and maintenance-week 24. Horizontal lines above the columns are the established cut-off concentrations for each type of lipid [21]. 


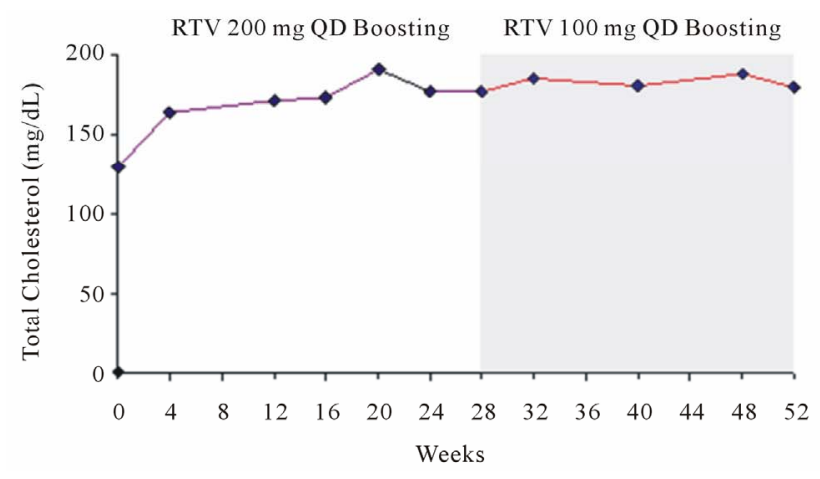

(a)

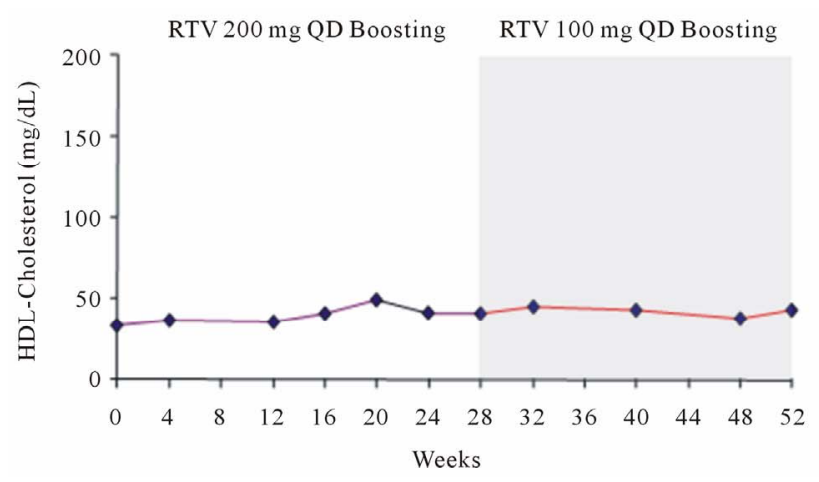

(c)

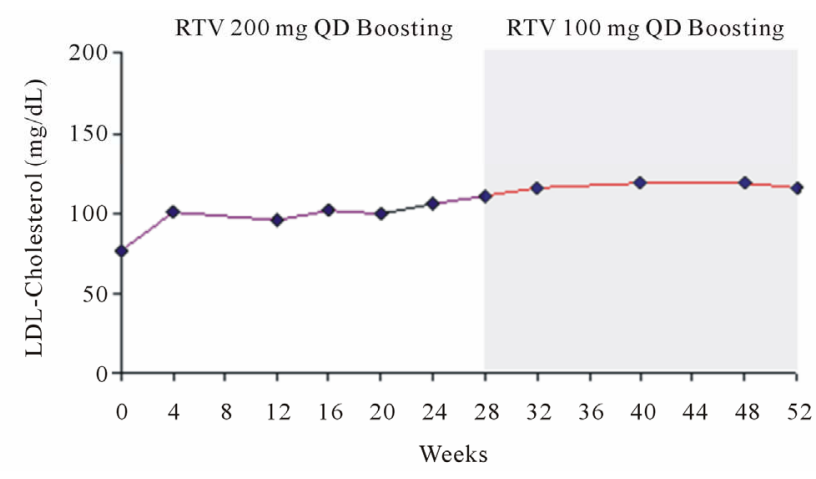

(b)

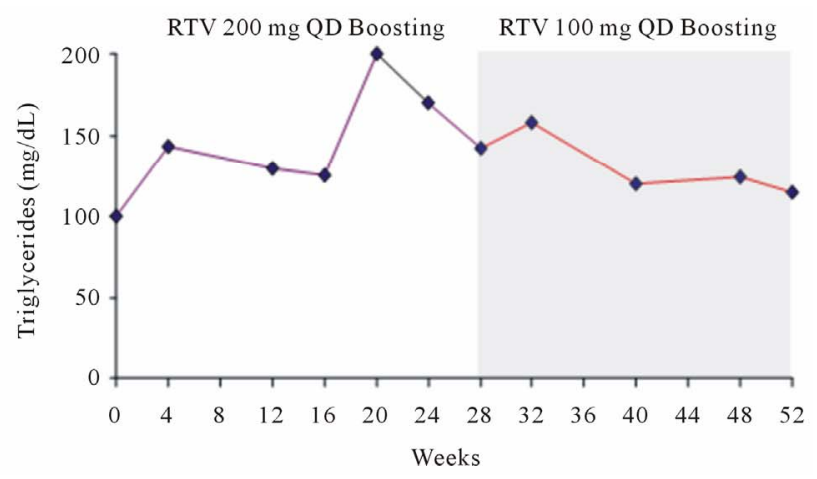

(d)

Figure 3. Changes from baseline in total cholesterol (a); LDL-cholesterol (b); HDL-cholesterol (c); and triglycerides (d).

reduction in the ritonavir dose to $100 \mathrm{mg}$ once daily, VLDL/chylomicrons decreased by $8 \%$ to $46 \%$ by maintenance-week 24 , the range of reduction differing by particle size. Similarly, during the induction phase, total LDL particles and LDL subclasses increased by 34 to $108 \%$, but these either decreased (as was the case with large LDL and IDL particles) or did not change (observed with total, small, medium-small, and very small LDL particles) following the decrease in ritonavir boosting dose. HDL particles and subclasses increased during induction by $27 \%$ to $113 \%$; following ritonavir dose reduc- tion, total and large HDL particle quantity did not change notably, but medium HDL particles decreased by $43 \%$ and small HDL particles increased by $16 \%$. Mean VLDL, LDL, and HDL particle size did not change from base- line during either the induction or maintenance phases of the study.

\section{Discussion}

The results of our study show that in HIV-infected patients stabilized on fosamprenavir/ritonavir $1400 \mathrm{mg} / 200$ $\mathrm{mg}$ plus abacavir/lamivudine $600 \mathrm{mg} / 300 \mathrm{mg}$ once daily, reduction in the ritonavir boosting dose to $100 \mathrm{mg}$ once daily with no other changes in the regimen maintains virologic suppression and CD4+ cell enhancement over the ensuing 24 weeks. These findings corroborate those of two other studies that investigated the clinical effect of halving ritonavir boosting to $100 \mathrm{mg}$ once daily in fosamprenavir regimens $[15,16]$. In the larger, statistically powered study, LESS, 229 previously antiretroviral-naïve patients stabilized (viral load $<400$ copies $/ \mathrm{mL}$ for at least 3 months) on fosamprenavir regimens boosted by 200 $\mathrm{mg}$ daily (200 mg once daily or $100 \mathrm{mg}$ twice daily) were randomized 2:1 to fosamprenavir/ritonavir $1400 \mathrm{mg} / 100$ mg once daily $(n=140)$ or to continuation of their current regimen with no change in background therapy $(\mathrm{n}=$ 69) [15]. At week 24 post-switch, virologic and immunologic responses were similar in the ritonavir $100 \mathrm{mg}$ and $200 \mathrm{mg}$ once-daily-boosted arms: viral load $<50$ copies $/ \mathrm{mL}$ in $92 \%$ versus $94 \%$ (missing or discontinuation equals failure analysis); frequency of virologic failure $8 \%$ versus $6 \%$; median CD4+ cell count 444 vs 453 cells $/ \mathrm{mm}^{3}$ above baseline. Similarly, in the direct comparative clinical trial APV109141, intent-to-treat-exposed: observed analysis showed viral load $<50$ copies/mL achieved by virtually the same proportion of antiretroviralnaïve patients on fosamprenavir plus abacavir/lamivudine regimens boosted by ritonavir $100 \mathrm{mg}$ once daily and $200 \mathrm{mg}$ daily (as a $100 \mathrm{mg}$ twice-daily regimen)- 
Table 2. Changes in lipid particle concentrations during the study.

\begin{tabular}{|c|c|c|c|c|c|c|c|c|c|}
\hline \multirow[t]{2}{*}{ Lipid Particle } & \multirow{2}{*}{$\begin{array}{c}\text { Baseline (A) } \\
\text { Mean }\end{array}$} & \multicolumn{3}{|c|}{ End of Induction (B) } & \multicolumn{5}{|c|}{ End of Maintenance (C) } \\
\hline & & Mean & $\begin{array}{l}\text { Change } \\
\text { from A }\end{array}$ & $\begin{array}{l}\text { \% Change } \\
\text { from A }\end{array}$ & Mean & $\begin{array}{l}\text { Change } \\
\text { from A }\end{array}$ & $\begin{array}{l}\text { \% Change } \\
\text { from A }\end{array}$ & $\begin{array}{l}\text { Change } \\
\text { from } B\end{array}$ & $\begin{array}{l}\% \text { Change } \\
\text { from } B\end{array}$ \\
\hline \multicolumn{10}{|c|}{$\begin{array}{l}\text { VLDL/Chylomicron } \\
\text { particles }(\mathrm{nmol} / \mathrm{L})\end{array}$} \\
\hline Total & 50.0 & 101.2 & +51.2 & $+102 \%$ & 73.5 & +23.5 & $+47 \%$ & -27.7 & $-27 \%$ \\
\hline Large & 1.5 & 2.7 & +1.2 & $+80 \%$ & 2.5 & +1.0 & $+67 \%$ & -0.2 & $-37 \%$ \\
\hline Medium & 19.3 & 51.3 & +32.0 & $+166 \%$ & 27.5 & +8.2 & $+42 \%$ & -23.8 & $-46 \%$ \\
\hline Small & 29.1 & 47.2 & +18.1 & $+62 \%$ & 43.4 & +14.3 & $+49 \%$ & -3.8 & $-8 \%$ \\
\hline \multicolumn{10}{|c|}{ LDL particles (nmol/L) } \\
\hline Total & 982.5 & 1314.6 & +332.1 & $+34 \%$ & 1297.5 & +315.0 & $+32 \%$ & -17.1 & $-0.1 \%$ \\
\hline IDL & 23.1 & 48.0 & +24.9 & $+108 \%$ & 38.1 & +15.0 & $+65 \%$ & -9.9 & $-21 \%$ \\
\hline Large & 189.5 & 379.5 & +190.0 & $+100 \%$ & 212.1 & +22.6 & $+12 \%$ & -167.4 & $-44 \%$ \\
\hline Small & 769.9 & 1041.0 & +271.1 & $+35 \%$ & 1041.4 & +271.5 & $+35 \%$ & +0.4 & $+0.04 \%$ \\
\hline Medium-small & 153.9 & 217.3 & +63.4 & $+41 \%$ & 213.6 & +59.7 & $+39 \%$ & -3.7 & $-2 \%$ \\
\hline Very small & 616.1 & 823.7 & +207.6 & $+34 \%$ & 827.7 & +211.6 & $+34 \%$ & +4.0 & $+0.5 \%$ \\
\hline \multicolumn{10}{|c|}{ HDL particles $(\mathrm{nmol} / \mathrm{L})$} \\
\hline Total & 20.0 & 27.5 & +7.5 & $+38 \%$ & 26.6 & +6.6 & $+33 \%$ & -0.9 & $-3 \%$ \\
\hline Large & 3.3 & 5.0 & +1.7 & $+52 \%$ & 5.0 & +1.7 & $+52 \%$ & 0 & $0 \%$ \\
\hline Medium & 2.3 & 4.9 & +2.6 & $+113 \%$ & 2.8 & +0.5 & $+22 \%$ & -2.1 & $-43 \%$ \\
\hline Small & 14.3 & 18.2 & +3.9 & $+27 \%$ & 21.1 & +6.8 & $+48 \%$ & +2.9 & $+16 \%$ \\
\hline \multicolumn{10}{|c|}{ Mean particle size (nm) } \\
\hline VLDL & 47.8 & 45.6 & -2.2 & $-5 \%$ & 44.7 & -3.1 & $-6 \%$ & -0.9 & $-2 \%$ \\
\hline LDL & 20.4 & 20.3 & -0.1 & $-0.5 \%$ & 20.4 & 0 & $0 \%$ & +0.1 & $+0.5 \%$ \\
\hline HDL & 8.8 & 8.9 & +0.1 & $+1 \%$ & 8.7 & -0.1 & $-1 \%$ & -0.2 & $-2 \%$ \\
\hline
\end{tabular}

Abbreviations: HDL, high-density lipoprotein; IDL, intermediate-density lipoprotein; LDL, low-density lipoprotein; VLDL, very-low-density lipoprotein.

$94 \%(84 / 89)$ and $93 \%(84 / 90)$, respectively - with a comparable median increase from baseline in CD4+ count of 149 and 140 cells $/ \mathrm{mm}^{3}$, respectively [7].

In our study, we saw no differences in the frequency of adverse events between the end of the ritonavir $200 \mathrm{mg}$ once-daily-boosted induction phase and the end of the 24-week ritonavir $100 \mathrm{mg}$ once-daily-boosted maintenance phase $(\mathrm{P}>0.05)$. A similar absence of notable differences in drug-related adverse event frequency was also observed in the LESS study over 24 weeks following the lowering of ritonavir boosting doses of fosamprenavir regimens from $200 \mathrm{mg}$ once daily to $100 \mathrm{mg}$ once daily (overall $7 \%$ versus $4 \%$, diarrhea $3 \%$ versus $1 \%$ ) [15]. This lack of a difference in tolerability between the study phases may have been due in part to patients having been on induction treatment for many weeks and the known reduction in adverse events, especially gastrointestinal tolerability, that takes place over time [22]. The time-bound nature of certain adverse events was observed in the 48-week SOLO clinical trial in which a substantial proportion of patients on fosamprenavir/ritonavir $1400 \mathrm{mg} / 200 \mathrm{mg}$ plus abacavir/lamivudine once daily who initially experienced drug-related nausea $(31 \%)$, diarrhea $(29 \%)$, vomiting $(15 \%)$, and headache $(10 \%)$ had abatement of these symptoms after a mean of $80,114,19$, and 92 days, respectively, usually without the need for remedial drug therapy (in $82 \%$ to $95 \%$ of cases) [3]. In contrast, in studies that have directly compared fosamprenavir/ritonavir $1400 \mathrm{mg} / 200$ $\mathrm{mg}$ once daily and $1400 \mathrm{mg} / 100 \mathrm{mg}$ once-daily regimens, the ritonavir $100 \mathrm{mg}$ regimen generally has been associated with fewer gastrointestinal side effects [7,17]. 
Thus, in APV109141, over 48 weeks, a lower proportion of HIV-infected patients taking fosamprenavir/ritonavir $1400 \mathrm{mg} / 100 \mathrm{mg}$ once daily plus abacavir/lamivudine (n = 106) than patients taking fosamprenavir/ritonavir 700 $\mathrm{mg} / 100 \mathrm{mg}$ twice daily plus the same nucleoside backbone $(\mathrm{n}=106)$ reported Grade 2 or higher drug-related adverse events in general (26\% vs $36 \%)$ and diarrhea in particular ( $<1 \%$ vs $12 \%)$ [7]. Furthermore, in a crossover pharmacokinetic study (COL10053) that compared 14day regimens of fosamprenavir/ritonavir $1400 \mathrm{mg} / 100$ $\mathrm{mg}$ once daily and fosamprenavir/ritonavir $1400 \mathrm{mg} / 200$ $\mathrm{mg}$ once daily in 41 healthy volunteers, the ritonavir 100mg-boosted regimen was associated with a lower frequency of gastrointestinal adverse events in general $(35 \%$ vs $56 \%$ ) and nausea in particular (11\% vs $27 \%$ ) [17].

The overall fasting lipid profile observed during both phases of the study showed favorable HDL-cholesterol increases balanced by unfavorable increases in total- and LDL-cholesterol, with the latter two lipids nevertheless remaining below the NCEP cutoff concentrations. Reduction in ritonavir boosting of the fosamprenavir 1400 $\mathrm{mg}$ once-daily regimen from $200 \mathrm{mg}$ to $100 \mathrm{mg}$ once daily led to a modest reduction in triglycerides, but little change in total-, LDL-, and HDL-cholesterol. This finding is consistent with the results of LESS at 24 weeks post-switch from ritonavir $200 \mathrm{mg}$ to $100 \mathrm{mg}$ once-daily boosting (median triglycerides $-21 \mathrm{mg} / \mathrm{dL}$, total cholesterol: $-1 \mathrm{mg} / \mathrm{dL}$, LDL-cholesterol: no change; HDLcholesterol: $-1 \mathrm{mg} / \mathrm{dL}$ ) [15], and of TELEX II at 4 weeks post-switch (median triglycerides $-35 \mathrm{mg} / \mathrm{dL}$, total-cholesterol $-17 \mathrm{mg} / \mathrm{dL}$, HDL-cholesterol $+2 \mathrm{mg} / \mathrm{dL}$ ) [16]. The more favorable effect on triglycerides of a oncedaily ritonavir $100 \mathrm{mg}$ plus fosamprenavir $1400 \mathrm{mg}$ regimen over the fosamprenavir regimen boosted by double the ritonavir dose was also noted in the direct comparative study APV109141 [7]. That study showed at 24 weeks only slightly less elevation in total-cholesterol ( +46 vs $+55 \mathrm{mg} / \mathrm{dL}$ median change from baseline) and LDL-cholesterol $(+37.5 \mathrm{vs}+47.2 \mathrm{mg} / \mathrm{dL}$ median change from baseline), but notably less elevation in triglycerides ( $+40 \mathrm{vs}+75 \mathrm{mg} / \mathrm{dL})$.

In the lipoprotein analysis, the reduction we observed in total VLDL/chylomicrons and all subclasses of VLDL lipoprotein after the ritonavir 200 to $100 \mathrm{mg}$ once daily switch coincided with the fall in triglycerides. This was to be expected because VLDL is the primary carrier of triglycerides, and so reduction in the former could lead to reduction in the latter [23]. Overall, this, taken along with the $16 \%$ decrease in small HDL particle concentration and the $44 \%$ and $21 \%$ reductions in LDL and IDL particle concentrations, respectively, could be perceived as positive changes from a cardiovascular risk perspective [23]. However, optimism regarding these changes must be tempered by the fact that the ritonavir 200 to 100 mg switch did not alter the concentrations of small, medium-small, or very-small LDL, which would have been desirable in view of their association with atherogenicity [23].

We did not evaluate how the switch from ritonavir 200 $\mathrm{mg}$ once daily to $100 \mathrm{mg}$ once daily could have impacted cardiovascular inflammation biomarkers. However, in a crossover study that compared 14-day regimens of ritonavir $100 \mathrm{mg}$ once daily and twice that ritonavir dose (given as $100 \mathrm{mg}$ twice daily) in healthy volunteers not taking other drugs, ritonavir $100 \mathrm{mg}$ once daily was associated with less elevation in the vascular inflammation biomarker sCD40L in plasma (12\% vs 19\%) [24]. Ritonavir $100 \mathrm{mg}$ twice daily, but not ritonavir $100 \mathrm{mg}$ once daily, significantly increased the biomarker adipophilin. The ritonavir $100 \mathrm{mg}$ once-daily and $100 \mathrm{mg}$ twice-daily regimens did not differ notably with respect to magnitude of change in HDL-cholesterol $(-6 \%$ vs $-10 \%)$ or in CD36 (-14\% vs $-16 \%)$. Neither regimen had any impact on the concentrations of the biomarkers hsCRP or sICAM-1.

Our study did not include a pharmacokinetic analysis to verify the attainment of virologically suppressive amprenavir concentrations with the ritonavir $100 \mathrm{mg}$ once-daily boosting regimen. However, LESS showed little difference in the amprenavir $\mathrm{C}_{\tau}$ achieved at week 24 in patients taking the fosamprenavir/ritonavir $1400 \mathrm{mg} /$ $100 \mathrm{mg}$ once-daily, $1400 \mathrm{mg} / 200 \mathrm{mg}$ once-daily, or 700 $\mathrm{mg} / 100 \mathrm{mg}$ twice-daily regimens $(1.84,1.78$, and 2.30 $\mu \mathrm{g} / \mathrm{mL}$, respectively) [15]. These $\mathrm{C}_{\tau}$ values are $12.6,12.2$, and 15.8-fold higher than the historical mean amprenavir protein binding $(90 \%)$ adjusted $\mathrm{IC}_{50}$ for wild-type $\mathrm{HIV}$ $(0.146 \mu \mathrm{g} / \mathrm{mL})$. Therefore, plasma amprenavir concentrations produced with the fosamprenavir/ritonavir 1400 $\mathrm{mg} / 100 \mathrm{mg}$ once-daily regimen in our study were expected to be several fold above this $\mathrm{IC}_{50}$. To date, ritonavir boosting doses below $100 \mathrm{mg}$ once daily for fosamprenavir regimens have not been investigated. However, a study by Matthias et al. [25] comparing the effect of ritonavir $50 \mathrm{mg}$ and ritonavir $100 \mathrm{mg}$ on hepatic CYP3A activity showed a $34 \%$ lower area under the plasma concentration-time curve of the CYP3A probe substrate drug midazolam with ritonavir $50 \mathrm{mg}$. Therefore, if one were to extrapolate these findings to amprenavir, a CYP3A substrate, it appears possible that a ritonavir 50 mg boosting dose could result in subtherapeutic amprenavir concentrations in some patients.

In this clinical trial the study medications were not supplied by the sponsor. Our study was limited by its small evaluable population due to the high dropout rate caused by erratic delivery of drugs to these indigent patients through the U.S. ADAP. The difficulty to ensure 
availability and consistent delivery of antiretroviral medication to impoverished HIV-infected patients through the ADAP has been documented elsewhere [26]. This underscores the challenge of enrolling patients on such programs into clinical trials because program restrictions/regulations may change over time and make initially medication-eligible patients ineligible later on. Our study was also limited by the lack of information collected regarding diet and exercise, both of which can impact lipids.

In conclusion, reducing once-daily ritonavir boosting from $200 \mathrm{mg}$ to $100 \mathrm{mg}$ in HIV-infected patients stabilized on once-daily fosamprenavir/abacavir/lamivudine generally maintained virologic suppression, enhanced CD4+ count, and improved triglycerides.

\section{Acknowledgements and Disclosures}

The authors gratefully acknowledge the study participants and the staff members at the University of Miami Miller School of Medicine who assisted the study investigator. The study was supported by a financial grant from GlaxoSmithKline. The results of this study were presented in part as Abstract/Poster 99 at the Annual Meeting of the American College of Clinical Pharmacy, Louisville, Kentucky, October 19-22, 2008.

\section{REFERENCES}

[1] H. A. Torres and R. C. Arduino, "Fosamprenavir Calcium Plus Ritonavir for HIV Infection," Expert Review of AntiInfective Therapy, Vol. 5, No. 3, 2007, pp. 349-363. doi:10.1586/14787210.5.3.349

[2] A. Hill, J. Van Der Lugt, W. Sawyer and M. Boffito, "How Much Ritonavir Is Needed to Boost Protease Inhibitors? Systematic Review of 17 Dose-Ranging Pharma- cokinetic Trials," AIDS, Vol. 23, No. 17, 2009, pp. 2237- 2245. doi:10.1097/QAD.0b013e328332c3a5

[3] J. C. Gathe Jr., P. Ive, R. Wood, D. Schürmann, N. C. Bellos, E. DeJesus, et al., "SOLO: 48-Week Efficacy and Safety Comparison of Once-Daily Fosamprenavir/Ritonavir Versus Twice-Daily Nelfinavir in Naive HIV-1Infected Patients," AIDS, Vol. 18, No. 11, 2004, pp. 15291537. doi:10.1097/01.aids.0000131332.30548.92

[4] S. A. Danner, A. Carr, J. M. Leonard, L. M. Lehman, F. Gudiol, J. Gonzales, et al., "A Short-Term Study of the Safety, Pharmacokinetics, and Efficacy of Ritonavir, an Inhibitor of HIV-1 Protease," New England Journal of Medicine, Vol. 333, No. 23, 1995, pp. 1528-1533. doi:10.1056/NEJM199512073332303

[5] G. Gatti, A. Di Biagio, R. Casazza, C. De Pascalis, M. Bassetti, M. Cruciani, et al., "The Relationship between Ritonavir Plasma Levels and Side-Effects: Implications for Therapeutic Drug Monitoring," AIDS, Vol. 13, No. 15, 1999, pp. 2083-2089. doi:10.1097/00002030-199910220-00011
[6] M. Sension and P. J. Piliero, "Ritonavir-Boosted Protease Inhibitors: Impact of Ritonavir on Toxicities in TreatmentExperienced Patients," Journal of the Association of Nurses in AIDS Care, Vol. 18, No. 1, 2007, pp. 36-47. doi:10.1016/j.jana.2006.11.003

[7] G. Carosi, A. Lazzarin, H. Stellbrink, G. Moyle, S. Rugina, S. Staszewski, et al., "Study of Once-Daily Versus TwiceDaily Fosamprenavir Plus Ritonavir Administered with Abacavir/Lamivudine Once Daily in Antiretroviral-Naïve HIV-1-Infected Adult Subjects," HIV Clinical Trials, Vol. 10, No. 6, 2009, pp. 356-367.

doi: $10.1310 /$ hct $1006-356$

[8] C. B. Hicks, E. DeJesus, L. M. Sloan, M. G. Sension, D. A. Wohl, Q. Liao, et al., "Comparison of Once-Daily Fosamprenavir Boosted with Either 100 or $200 \mathrm{mg}$ of Ritonavir, in Combination with Abacavir/Lamivudine: 96week Results from COL100758," AIDS Research and Human Retroviruses, Vol. 25, No. 4, 209, pp. 395-403.

[9] S. De Wit, B. Poll, C. Necsoi and N. Clumeck, "Fosamprenavir Boosted with a Single $100 \mathrm{mg}$ Capsule of Ritonavir as Part of a Once Daily First Line Regimen in Naïve Patients," 8th International Congress on Drug Therapy in HIV Infection, Glasgow, 12-16 November 2006, p. 17.

[10] P. Muret, D. Montange, D. Bettinger, J. Faller, B. Martha and G. Beck-Wirth, "Assessment of Amprenavir Plasma $\mathrm{C}_{\min }$ Levels in Patients Receiving Once-Daily Fos-Amprenavir in Combination with Either 100 or 200 mg Ritonavir," 8th International Workshop on Clinical Pharmacology of HIV Therapy, Budapest, 16-18 April 2007, p. 26.

[11] K. Y. Smith, W. G. Weinberg, E. De Jesus, M. A. Fischl, Q. Liao, L. L. Ross, et al., "Fosamprenavir or Atazanavir Once Daily Boosted with Ritonavir $100 \mathrm{mg}$, Plus Tenofovir/Emtricitabine, for the Initial Treatment of HIV Infection: 48-Week Results of ALERT," AIDS Research and Therapy, Vol. 5, No. 5, 2008, pp. 1-10.

[12] G. Blick, P. Greiger-Zanlungo, V. Plasencia, S. Gretz, J. Han, D. DuPree, et al., "Long-Term Efficacy and Safety of Fosamprenavir (FPV) $1400 \mathrm{mg}$ Once Daily (QD) Boosted by Ritonavir (r) $100 \mathrm{mg}$ QD in AntiretroviralNaïve HIV+ Patients and in Antiretroviral-Experienced Patients Switched to FPV/r Due to Intolerance to Prior Regimens: BOLD100 (COL109766)," Annual Meeting of the American College of Clinical Pharmacy, Denver, 14-17 October 2007, p. 110E.

[13] R. Hsu, K. Walker-Reed and E. Acosta, "Fosamprenavir (FPV) with Low-Dose Ritonavir (RTV) Once Daily (QD) in HIV-Infected Subjects," 7th International Workshop on Clinical Pharmacology of HIV Therapy, Lisbon, 20-22 April 2006, p. 71.

[14] E. Latuada, M. Lanzafame, C. Grosso, F. Soldani, F. Corsini, S. Storato, et al., "Optimal Fosamprenavir Regimen to Prevent Lipid Abnormalities," Acta Bio-Medica, Vol. 80, No. 3, 2009, pp. 200-202.

[15] C. Cohen, E. DeJesus, A. La Marca, B. Young, L. Yau, L. Patel, et al., "Similar Virologic and Immunologic Efficacy with Fosamprenavir Boosted with $100 \mathrm{mg}$ or $200 \mathrm{mg}$ 
of Ritonavir in HIV-Infected Patients: Results of the LESS Trial," HIV Clinical Trials, Vol. 11, No. 5, 2010, pp. 239-247. doi:10.1310/hct1105-239

[16] D. A. Parks, H. C. Jennings, C. Taylor, G. E. Pakes and E. P. Acosta, "Steady-State Amprenavir, Tenofovir, Emtricitabine, and Ritonavir Pharmacokinetics before and after Reducing Ritonavir Boosting of a Fosamprenavir/Tenofovir/Emtricitabine Regimen from $200 \mathrm{mg}$ to $100 \mathrm{mg}$ Once Daily (TELEX II)," HIV Clinical Trials, Vol. 10, No. 3, 2009, pp. 160-167. doi:10.1310/hct1003-160

[17] P. J. Ruane, A. D. Luber, M. B. Wire, Y. Lou, M. J. Shelton, C. T. Lancaster, et al., "Plasma Amprenavir Pharmacokinetics and Tolerability Following Administration of 1400 Milligrams of Fosamprenavir Once Daily in Combination with Either 100 or 200 Milligrams of Ritonavir in Healthy Volunteers," Antimicrobial Agents and Chemotherapy, Vol. 51, No. 2, 2007, pp. 560-565. doi:10.1128/AAC.00560-06

[18] M. Sale, B. M. Sadler and D. S. Stein, "Pharmacokinetic Modeling and Simulations of Interaction of Amprenavir and Ritonavir," Antimicrobial Agents and Chemotherapy, Vol. 46, No. 3, 2002, pp. 746-754. doi:10.1128/AAC.46.3.746-754.2002

[19] R. Wood, K. Arasteh, H-J. Stellbrink, E. Teofilo, F. Raffi, R. B. Pollard, et al., "Six-Week Randomized Controlled Trial to Compare the Tolerabilities, Pharmacokinetics, and Antiviral Activities of GW433908 and Amprenavir in Human Immunodeficiency Virus Type 1-Infected Patients," Antimicrobial Agents and Chemotherapy, Vol. 48, No. 1, 2004, pp. 116-123. doi:10.1128/AAC.48.1.116-123.2004

[20] Food and Drug Administration, "FDA Approves Administration of LEXIVA with Lower Dose of 'Boosting' Medication Ritonavir," GlaxoSmithKline, Inc., Mississauga, 2007. http://us.gsk.com/ControllerServlet?appId=4\&pageId $=40$ 2\&newsid $=1158$
[21] National Cholesterol Education Program (NCEP) Expert Panel on Detection, Evaluation, and Treatment of High Blood Cholesterol in Adults (Adult Treatment Panel III), "Third Report of the National Cholesterol Education Program (NCEP) Expert Panel on Detection, Evaluation, and Treatment of High Blood Cholesterol in Adults (Adult Treatment Panel III): Final Report," Circulation, Vol. 106, No. 25, 2002, pp. 3143-3421.

[22] T. Hawkins, "Understanding and Managing the Adverse Effects of Antiretroviral Therapy," Antiviral Research, Vol. 85, No. 1, 2010, pp. 201-209. doi:10.1016/j.antiviral.2009.10.016

[23] J. D. Brunzell, M. Davidson, C. D. Furberg, R. B. Goldberg, B. V. Howard, J. H. Stein, et al., "Lipoprotein Management in Patients with Cardiometabolic Risk: Consensus Conference Report from the American Diabetes Association and the American College of Cardiology Foundation," Journal of the American College of Cardiology, Vol. 51, No. 15, 2008, pp. 1512-1524. doi:10.1016/j.jacc.2008.02.034

[24] S. Collot-Teixetra, F. De Lorenzo, L. Waters, C. Fletcher, D. Back, S. Mandalia, et al., "Impact of Different LowDose Ritonavir Regimens on Lipids, CD36, and Adipophilin Expression," Clinical Pharmacology and Therapeutics, Vol. 85, No. 4, 2009, pp. 375-378. doi:10.1038/clpt.2008.243

[25] A. Mathias, S. West, J. Hui and B. P. Kearney, "DoseResponse of Ritonavir on Hepatic CYP3A Activity and Elvitegravir Oral Exposure," Clinical Pharmacology and Therapeutics, Vol. 85, No. 1, 2009, pp. 64-70. doi:10.1038/clpt.2008.168

[26] I. V. Bassett, C. Farel, E. D. Szmuilowicz and R. P. Walensky, "AIDS Drug Assistance Programs in the Era of Routine HIV Testing," Clinical Infectious Diseases, Vol. 47, No. 5, 2008, pp. 695-701. doi:10.1086/590936

\section{Appendix}

ADAP: AIDS drug assistance program

CD36: Scavenger receptor

HDL: High-density lipoprotein

hsCRP: Highly specific C-reactive protein

$\mathrm{IC}_{50}: 50 \%$ Inhibitory concentration

IDL: Intermediate-density lipoprotein

LDL: Low-density lipoprotein

LLOQ: Lower limit of quantitation

NCEP: National cholesterol education program

NMR: Nuclear magnetic resonance

sCD40L: Soluble CD40 ligand

sICAM-1: Soluble intercellular adhesion molecule 1

VLDL: Very low-density lipoprotein 